\title{
Sobre a ideia de dramatização em Gilles Deleuze
}

\author{
Veronica Damasceno \\ vmdamasceno@gmail.com \\ Universidade Federal do Rio de Janeiro, Rio de Janeiro, Brasil
}

resumo Este artigo visa introduzir a noção de dramatização em Gilles Deleuze. Trata-se da subversão das clássicas perguntas metafísicas que justificam as essências e (as ideias). Uma distribuição de diferenças determina a atualização das ideias. 0 método de dramatização envolve processos de diferenciação. Diferenças internas, relativas a blocos de espaço-tempo criam condições para os conceitos. Um campo intensivo e diferencial de forças faz emergir um teatro especial de virtualidades e uma expressividade das ideias. A realidade não é dada, mas dramatizada por forças não individuais e subjetividades larvares. 0 método de dramatização está aquém do conhecimento e até mesmo de toda consolidação que a filosofia ganha com os conceitos. 0 artigo procurará ainda indicar os vínculos da dramatização com os mundos incompossíveis de Leibniz e com o cinema de David Lynch. palavras-chave dramatização; virtual, ideia, incompossível; individuação; conceito

Pensar é habitar, construir a imanência. A filosofia, para Gilles Deleuze, começa com a criação conceitual e ao mesmo tempo com a instauração do plano de imanência (DELEUZE; GUATTARI, 1992, p.58). Em O que é a filosofia?, Deleuze, juntamente com Félix Guattari, sustentam que a filosofia é uma disciplina extremamente criadora, criar conceitos é algo intrínseco à filosofia.

Todavia, criar conceitos, assim como ter ideias é extremamente dificil. Só criamos por uma necessidade imperiosa, algo que violenta o pensamento e nos conduz, nos leva a pensar, caso contrário, continuamos no plano das opiniões correntes. Em sua conferência aos estudantes de cine- 
ma, intitulada $O$ que é o ato de criação?, Deleuze afirma que as ideias, quando as temos, devemos recebê-las como uma espécie de festa, dada a dificuldade que é ter uma ideia. Nesse sentido, assinala: “[...] o que significa ter uma ideia? [...] todo mundo sabe muito bem que ter uma ideia é algo que acontece raramente, é uma espécie de festa, pouco corrente" (DELEUZE, 2003, p.291).

Em O que é a filosofia? Deleuze, com Guattari, retoma a problemática da ideia introduzindo sua relação com o caos. Para esses pensadores, os verdadeiros artistas e poetas são aqueles que abrem uma fenda no guardasol e o rasgam até o firmamento a fim de possibilitar a passagem do caos livre. O caos consiste, precisamente, nos movimentos e velocidades infinitas com que as determinações surgem e se apagam, isto é, na impossibilidade de uma relação entre duas determinações, pois duas determinações não coexistem, já que quando uma surge a outra já desapareceu. O caos desfaz no infinito toda e qualquer consistência. A arte almeja criar um finito que restitua o infinito; traça um plano de composição que suporta monumentos ou sensações compostas, a partir de figuras estéticas.

O que define a relação da arte com a filosofia, isto é, estas duas formas de pensamento é seu enfrentamento com o caos; arte e filosofia traçam planos sobre o caos. A filosofia, em sua tentativa de salvar o infinito, lhe dá uma consistência: "ela traça um plano de imanência, que leva até o infinito acontecimentos ou conceitos consistentes [...]" (DELEUZE, GUATTARI, 1992, p.248). Nesse sentido, o plano de imanência age como um crivo, ou uma peneira, que seleciona tais movimentos e velocidades caóticas para articulá-los com os conceitos filosóficos.

O problema da filosofia é, pois, adquirir uma consistência sem nada perder do infinito, no qual o pensamento mergulha. O problema da arte é trazer do caos as velocidades e movimentos infinitos para articulá-los com seus seres de sensação, agregados sensíveis. A esse respeito, o plano de composição da arte seleciona do caos movimentos e velocidades para articulá-los com os afectos e perceptos artísticos. Entretanto, a todo momento, tentamos nos proteger do caos, queremos a todo instante um pouco de ordem para nos proteger do caos, como observam Deleuze e Guattari:

Pedimos somente um pouco de ordem para nos proteger do caos.

Nada é mais doloroso, mais angustiante do que um pensamento que escapa a si mesmo, ideias que fogem, que desaparecem apenas 
esboçadas, já corroídas pelo esquecimento ou precipitadas em outras, que também não dominamos (DELEUZE, GUATTARI, 1992, p.259)

Os autores reclamam ainda da perda das ideias e consequentemente da necessidade de nos agarrarmos à opiniões prontas e ao encadeamento de ideias, a partir de regras necessárias e constantes. A associação de ideias nos dá regras protetoras, como a semelhança, a contiguidade e a causalidade. Tais regras possibilitam colocar um pouco de ordem em nossas ideias e ao mesmo tempo impedir a fantasia, o delírio ou mesmo a loucura. Entretanto, para esses pensadores, tudo isso somente contribui para a formação de mais uma opinião, como um guarda-sol que nos protege do caos.

A esse respeito, nos lembram os autores, Lawrence, em um texto violentamente poético, descreve o que a poesia faz:

...os homens não deixam de fabricar um guarda-sol que os abriga, por baixo do qual traçam um firmamento e escrevem suas convenções, suas opiniões; mas o poeta, o artista abre uma fenda no guarda-sol, rasga até o firmamento, para fazer passar um pouco do caos livre e tempestuoso e enquadrar numa luz brusca, uma visão que aparece através da fenda, primavera de Wordsworth, ou maçã de Cézanne, silhueta de Macbeth ou de Ahab. Então, segue a massa dos imitadores, que remendam o guarda-sol, com uma peça que parece vagamente com a visão; e a massa dos glosadores que preenchem a fenda com opiniões: comunicação. Será preciso sempre outros artistas para fazer outras fendas, operar as necessárias destruições, talvez cada vez maiores, e restituir assim, a seus predecessores, a incomunicável novidade que não mais se podia ver (DELEUZE, GUATTARI, 1992, p.261-262).

Grandes artistas produzem uma fissura, rasgam o guarda-sol, destroem o firmamento para que o caos livre possa passar e, então, criar sua obra de arte, a novidade, que o guarda-sol intenta proteger. A arte requer uma página em branco ou uma tela virgem. Entretanto, a tela ou a página estão cobertas de clichês preexistentes, preestabelecidos, de que é preciso, antes de tudo, apagá-las, limpá-las ou mesmo destrui-las para que o ar vindo do caos possa passar e trazer a visão ou imagem.

Assim como a arte, a filosofia também luta com o caos, mas para darlhe uma consistência. Entre a filosofia e o caos encontramos um abismo 
ou oceano. Um conceito filosófico difere de um conjunto de ideias associadas, de uma ordem de razões ou de uma série de razões ordenadas e, sobretudo, de uma opinião. Não atingimos o conceito submetendo os fenômenos a princípios de associação de ideias, ou as coisas aos princípios ordenadores das razões. É preciso antes diferenciar ideias correntes de ideias vitais: o que é necessário para umas não é suficiente para outras. As ideias vitais são aquelas que devemos criar. Para alcançar o conceito é preciso ultrapassar a associação de ideias - visto que elas se fazem somente como imagens e sua ordenação se faz por abstração - e atingir rapidamente objetos mentais que se determinam como pura realidade.

Arte e filosofia têm uma ligação de troca e de intimidade, já que ambas as disciplinas são extremamente criadoras. Criar conceitos é tão dificil quanto produzir uma imagem visual, sonora ou verbal. Por isso não há nenhum privilégio ou hierarquia entre essas duas disciplinas. Arte e filosofia traçam linhas melódicas estrangeiras entre si, porém intrínsecas.

Quando um grande filósofo surge, acontece o mesmo que com um artista ou um poeta, como afirmou Lawrence: "abre uma fenda no guarda-sol, rasga até o firmamento, para fazer passar um pouco do caos livre e tempestuoso e enquadrar numa luz brusca, uma visão que aparece através da fenda" (DELEUZE, GUATTARI, 1992, p.261). Foi assim com Gilles Deleuze: este grande pensador, que soube inovar o modo de fazer filosofia, entretanto, sem perder o rigor conceitual necessário ao pensamento. Sua criação, sem dúvida, advém da História da Filosofia, a qual ele dedicou parte de sua obra. Os conceitos criados por Deleuze remetem, quase sempre, a fragmentos de conceitos de outros pensadores, a partir dos quais ele cria os seus. No entanto, não se trata de articular ideias e conceitos somente com outros pensadores, mas também com artistas, escritores, cineastas. Para cada ideia um conceito, que se constitui por seus componentes internos - endo-consistência - e externos - exo-consistência conforme o problema colocado, para compor o plano que ele traça, povoado por singularidades.

A dramatização, por exemplo, se compõe de ideias e fragmentos de conceitos criados por Leibniz, Kant, Bergson. A dramatização é uma espécie de embrião para o trabalho que Deleuze desenvolverá em sua obra posterior. Essa noção aparece, inicialmente em 1963, em Nietzsche e a filosofia, posteriormente em 1967, em seu Comunicado e em 1968, em 
Diferença e repetição. Em Nietzsche e a filosofia, trata-se, em linhas gerais, de retirar o pathos dialético e cristão do drama, no trágico, para que o drama se torne método de dramatização, como assinala Deleuze:

Relacionar um conceito com a vontade de potência, para localizar o sintoma de uma vontade, sem a qual não poderia sequer ser pensado, nem o sentimento experimentado, nem a ação empreendida. Esse método corresponde à questão trágica, ele é o próprio método trágico. Se eliminarmos da palavra 'drama' todo pathos dialético e cristão que lhe compromete seu sentido, ela é método de dramatização (DELEUZE, 1963, p.89)

\section{Ideia e dramatização}

Em seu Comunicado à Sociedade Francesa de Filosofia, Gilles Deleuze apresenta-nos $O$ método de dramatização, texto essencial para a compreensão de seu pensamento ${ }^{1}$. Segundo o comentário de Schérer, essa comunicação versa sobre o devir do pensamento, o processo de sua produção nas dinâmicas espaciotemporais que requerem um espaço topológico. Ela pretende responder à questão: "Como as ideias vêm ao espírito?" (SCHÉRER, 1998, p.47), e ao fazê-lo Deleuze nos remete a "um campo intensivo de forças no qual as séries entram em ressonância; elas fulguram como o raio que jorra entre intensidades diferentes" (SCHÉRER, 1998, p.47).

O problema levantado nesse importante Comunicado de Deleuze diz respeito à emergência da Ideia. A Ideia constitui-se como um verdadeiro drama para o pensamento, já que se encontra sob o sistema da representação, numa instância pré ou anterepresentativa: "sob a representação há sempre a Ideia e seu fundo distinto-obscuro, um 'drama' sob todo logos" (DELEUZE, 2006, p.139). A dramatização da Ideia constitui, com efeito, a própria instância filosófica dos problemas.

Trata-se, portanto, de subverter a clássica pergunta metafisica, acerca de O que é? Essa nobre questão, tão cara ao Pensamento Antigo, pelas perguntas quanto? Como? Onde? Em que caso? Quando?, pois essas perguntas são mais propícias para se atingir a essência ou Ideia. Segundo a perspectiva de Deleuze, no contexto da história da filosofia como um todo é dificil encontrar um filósofo que tenha procedido somente em termos de $O$ que 
é? Essa pergunta só anima, em Platão, os diálogos chamados aporéticos, porque desde que a dialética tornou-se algo sério, ela passou a fazer perguntas do tipo: quem? no Político; quanto? no Filebo; onde e quando? no Sofista; e em que caso? no Parmênides. Mesmo Hegel ao servir-se dessa pergunta permanece tratando a essência de forma vazia e abstrata, pois sua dialética parece não separar-se do movimento da contradição. Por isso, Hegel é levado a substituir a instância do problemático pela instância do negativo. O resultado é uma dialética abstrata e desnaturada onde a Ideia corresponde à contradição entre a essência e o inessencial.

Para Deleuze, a Ideia só pode ser pensada segundo um outro procedimento, distinto da contradição e que teria sido esboçado por Leibniz. Esse processo é o da vice-dicção no qual o inessencial compreende o essencial, e o compreende submetido a um caso, sob o caso: "a subsunção sob 'o caso' forma uma linguagem original de propriedades e acontecimentos" (DELEUZE, 2006, p.131).

O procedimento da vice-dicção possibilita à Ideia ser concebida como uma multiplicidade, em toda sua dramaticidade. Isso quer dizer que a Ideia já não pode mais ser pensada nem como una nem como múltipla, ou ainda, como a síntese do uno e do múltiplo ao mesmo tempo: a ideia é, ela própria, uma multiplicidade. Ao tomar a multiplicidade como um substantivo e ao designar um domínio no qual a Ideia se encontra muito mais próxima do acidente do que da essência abstrata, Deleuze postula que sua determinação depende das questões: quem?, como?, quanto?, onde?, quando?, e em que caso? Os novos modos de determinação que essas questões revestem é que traçam as verdadeiras coordenadas espaciotemporais, segundo as quais a Ideia pode emergir dinamicamente.

A emergência dos dinamismos que envolvem a Ideia permite diferenciá-la segundo vários aspectos fundamentais: qualidade e espécie, partição, composição ou organização: "não há qualidade sem uma extensão que a subentenda [...] nem espécie sem partes ou pontos orgânicos. As partes são o número da espécie, como a espécie, a qualidade das partes" (DELEUZE, 2006, p.131).É sob esses aspectos que se encontram as condições segundo as quais as coisas são representadas.

Os dinamismos espaciotemporais que envolvem as ideias correspondem a "agitações do espaço, escavação do tempo, puras sínteses de velocidade, de direções e de ritmos” (DELEUZE, 2006, p.131). Todos os carac- 
teres mais gerais das ramificações, bem como as classificações genéricas e específicas dependem de tais dinamismos ou direções de desenvolvimento. Se não houvesse a determinação dos dinamismos sub-representativos não poderia haver nenhuma divisão lógica no conceito.

Esses dinamismos só se produzem em um campo intensivo, que implica, portanto, uma distribuição profunda de diferenças de intensidade, puras intensidades, preexistentes à toda qualidade e extensão. Esse campo intensivo é um meio de individuação. A individuação é a condição prévia para que a especificação e a repartição operem num dado sistema. As diferenças de intensidade devem entrar em comunicação, para tanto é preciso haver um diferenciante da diferença que relaciona o diferente ao diferente. A individuação depende, portanto, de um precursor sombrio, invisível, que é o agente da comunicação ou do cruzamento entre as séries de diferença.

Esse precursor induz fenômenos de ajustamento entre as séries de ressonância interna no sistema e de movimentos forçados sob a forma de uma amplitude que transborda as próprias séries de base. É precisamente sob todas essas condições que um sistema se preenche de qualidades e se desenvolve em extensão. É o conjunto dessas condições que determina os dinamismos espaciotemporais que são geradores dessas qualidades e dessas extensões.

Esses dinamismos engendram sujeitos, sujeitos larvares, ainda não qualificados ou inteiramente compostos, sujeitos embrionários, capazes de suportar a pressão de uma ressonância interna ou a amplitude de um movimento forçado. O pensamento como dinamismo próprio ao sistema filosófico, talvez seja um desses movimentos terríveis inconciliáveis com um sujeito formado, qualificado e composto como aquele do cogito na representação.

O conjunto dessas determinações - campo de individuação, séries de diferenças intensivas, precursor sombrio, ajustamento, ressonância e movimento forçado, sujeitos larvares, dinamismos espaciotemporais - designam as coordenadas múltiplas que correspondem às questões quanto?, quem?, como?, onde? e quando?

De fato esses dinamismos trabalham sob todas as formas e extensões qualificadas da representação e constituem, não um desenho, mas um conjunto de linhas abstratas saídas de uma profundidade inextensiva e informal. "Estranho teatro feito de determinações puras, agitando o 
espaço e o tempo, agindo diretamente sobre a alma, tendo por atores as larvas - e para o qual Artaud havia escolhido a palavra crueldade" (DELEUZE, 2006, p.134).

Essas linhas abstratas formam um drama sob a trama dos conceitos. Sob um conceito dado pode-se sempre encontrar um drama, sob as divisões e especificações do conceito no mundo da representação agem dinamismos dramáticos que os determinam e a toda representação possível.

O que Deleuze chama drama assemelha-se particularmente ao esquema kantiano. O esquema, segundo Kant, é uma determinação a priori do espaço e do tempo que corresponde a um conceito: o mais curto é, segundo a leitura deleuziana, o drama, o sonho ou antes, o pesadelo da linha reta. É exatamente o dinamismo que divide o conceito de linha em reta e curva e que permite medir a curva em função da reta. O que permanece, entretanto, ainda inteiramente misterioso é o modo pelo qual o esquema tem esse poder em relação ao conceito.

Segundo Deleuze, de um certo modo, todo o pós-kantismo tentou elucidar o mistério dessa arte oculta, segundo a qual as determinações dinâmicas espaciotemporais têm verdadeiramente o poder de dramatizar um conceito, apesar de eles serem de uma natureza inteiramente diferente do conceito.

O drama que se desenrola sob os conceitos parece sugerir que à Ideia deva corresponder dois aspectos determinantes da diferenciação. Por um lado, a Ideia consiste em um conjunto de relações diferenciais entre elementos desprovidos de forma sensível e de função e que só existem por sua determinação recíproca. Nesse caso, encontramo-nos diante de elementos ideais, ou seja, sem figura e sem função, mas reciprocamente determinados numa rede de relações diferenciais. Por outro lado, às relações diferenciais correspondem distribuições de singularidades, repartições de pontos notáveis e ordinários, de modo que um ponto notável engendra uma série prolongável sobre todos os pontos ordinários até a vizinhança de outra singularidade.

A Ideia aparece, portanto, como multiplicidade que deve ser percorrida em dois sentidos: do ponto de vista da variação das relações diferenciais e do ponto de vista da repartição de singularidades que correspondem a certos valores dessas relações. O que Deleuze chama de drama sugere esse duplo percurso ou essa dupla determinação recíproca e completa. 
Dois problemas decorrem daí: em primeiro lugar, a Ideia assim definida não dispõe de nenhuma atualidade. Ela é virtual, pura virtualidade. Todas as relações diferenciais em virtude da determinação recíproca, e todas as repartições de singularidade, em virtude da determinação completa, coexistem na multiplicidade virtual das ideias. Em segundo lugar, a Ideia só se atualiza quando suas relações diferenciais se encarnam nas espécies ou qualidades separadas e onde as singularidades concomitantes se encarnam numa extensão que corresponde a essa qualidade. A espécie ou a qualidade não se assemelha, portanto, às relações diferenciais que ela encarna, nem as singularidades assemelham-se à extensão organizada que as atualiza. A Ideia só se atualiza por diferenciação; atualizar-se é, pois, diferenciar-se.

Desse modo, é preciso atribuir maior importância à diferença das duas operações: diferenciar e diferençar ${ }^{2}$. A Ideia não é inteiramente diferença$d a$, porque lhe faltam qualidades e partes necessárias. Mas ela é absolutamente diferenciada porque ela dispõe de relações e singularidades que se atualizarão sem semelhança nas qualidades e partes.

Parece, portanto, que cada coisa tem sempre duas metades ímpares, dessemelhantes e dessimétricas. Cada uma dessas metades se subdivide ainda em duas outras: uma metade ideal, que mergulha no virtual e constitui-se por relações diferenciais e singularidades concomitantes; outra metade atual, constituída pelas qualidades que encarnam as relações diferenciais e as partes que encarnam as singularidades concomitantes.

Se chamamos distinto o estado da Ideia plenamente diferenciada e claro o estado da Ideia atualizada, ou seja, diferençado, então devemos romper com a regra de proporcionalidade do claro e do distinto. A Ideia em si não é clara e distinta, como pretendia Descartes, ao contrário, distinta e obscura. É nesse sentido que Deleuze pode afirmar que a Ideia é dionisíaca, distinção obscura indiferenciada e determinada.

Uma tal "distinção obscura" permite a Deleuze afirmar o continuum ideal do mundo de Leibniz. Continuidade sem homogeneidade, onde coexistem variações de relações diferenciais e de distribuições de singularidades nômades. Imagem da embriaguês, do fundo dionisíaco sob a ordenação apolínea.

Os dinamismos espaciotemporais no seio dos campos de individuação determinam a atualização das ideias nos aspectos diferenciados do objeto. 
Para cada conceito dado é preciso encontrar a Ideia que opera sob esse conceito. A Ideia e seu campo de individuação, os sistemas que a envolvem, os dinamismos que a determinam: "somente sob essas condições é que podemos penetrar no mistério da divisão do conceito" (DELEUZE, 2006, p.139). O método de dramatização envolve todas essas questões e libera um cortejo de questões: em que caso?, quem?, como? quanto? e onde? Sob a representação há sempre um drama, sob o claro e o distinto há sempre o distinto e obscuro, um drama sob o logos.

\section{Os incompossiveis de Leibniz}

O extraordinário mundo de Leibniz nos coloca diante de um continuum ideal. Essa continuidade não se define pela homogeneidade, mas pela coexistência de variações, relações diferenciais e singularidades. O estado desse mundo se expressa nas imagens do rumor, do sonho, da embriaguez, do desfalecimento. Imagens que dão testemunho do fundo dionisíaco sob a aparente filosofia apolínea.

O mundo de Leibniz comporta, nessa visão de Deleuze, tanto a compossibilidade quanto a incompossibilidade. Esse mundo nada tem a ver com a contradição, mas com a convergência e a divergência. É a convergência das séries que define a compossibilidade, cada uma delas se constrói sob a vizinhança entre singularidades. A incompossibilidade dos mundos surge quando as séries divergem. O melhor dos mundos é o que compreende o máximo de relações e singularidades com a condição de manter uma continuidade ou de um máximo de convergência de séries. Desse modo, formam-se essências individuais ou mônadas.

Leibniz assinala que o mundo não existe fora das mônadas que o exprimem e ao mesmo tempo afirma que Deus, em relação às mônadas, criou o mundo. Nesse sentido, observa Deleuze: "Deus não criou Adão pecador, mas o mundo em que Adão pecou” (DELEUZE, 2006, p.138). Isso significa que as singularidades do mundo são princípio para a constituição das individualidades. Cada indivíduo se recobre de singularidades e exprime as relações entre elas a partir de seu próprio corpo. Desse modo, o mundo exprimido só preexiste virtualmente às individualidades expressivas e, portanto, não existe atualmente fora dessas individualidades 
que o exprimem. É esse processo contínuo de individuação que determina a encarnação das relações e singularidades do mundo ideal nas qualidades e extensos que se encontram entre os indivíduos.

O fundo povoado por relações e singularidades, a constituição que se desdobra a partir dele, das essências individuais, bem como a determinação que se segue configuram o método de vice-dicção que constitui uma teoria das multiplicidades, que consiste sempre em subsumir sob o caso. Nesse sentido, em A dobra: Leibniz e o barroco (DELEUZE, 1991), Deleuze demonstra como as proposições Adão pecou e Adão não pecou, certamente contraditórias entre si, explicitam o procedimento de vice-dicção quando acrescidas de uma outra correlação explicando assim que a proposição Adão não pecou não é contraditória em si. Essa relação não se estabelece entre um Adão e outro, mas sim entre Adão não-pecador e o mundo no qual Adão pecou. Todavia, uma vez que o mundo em que Adão pecou encontra-se em Adão, a contradição retorna. Mas este mundo compreende uma infinidade de outros mundos ou mônadas. Entre os dois mundos há uma outra relação que não é de contradição - embora a contradição surja entre os sujeitos que os compreendem - mas sim de vice-dicção. A essa nova relação Leibniz designa incompossibilidade, uma correlação original que não se reduz à contradição; é uma diferença e não uma negação.

O mundo de Leibniz é constituído por uma infinidade de séries convergentes que se prolongam entre si, ao redor de pontos singulares. Nesse sentido, observa Deleuze: "Assim, cada indivíduo, cada mônada individual expressa o mesmo mundo em seu conjunto, embora só expresse claramente uma parte desse mundo, uma série ou mesmo uma sequência finita" (DELEUZE, 1991, p.104). Entretanto, um outro mundo emerge quando as séries obtidas divergem na vizinhança das singularidades. Desse modo, ao conjunto das séries convergentes e prolongáveis que compõem um mundo e ao conjunto das mônadas que expressam o mesmo mundo Deleuze atribui a designação compossíveis, pois expressam uma compossibilidade, séries convergentes ou mundos compossíveis, por exemplo, Adão pecador, César imperador, Cristo salvador.. As séries divergentes e que pertencem a dois mundos possíveis e as mônadas que expressam cada uma um mundo próprio, singular e, portanto, diferente do outro, como César imperador e Adão não pecador, são denominados 
incompossíveis. A vice-dicção expressa, pois, a divergência eventual das séries e define a incompossibilidade.

Leibniz estabelece uma infinidade de mundos possíveis, mas de modo algum reintroduz uma dualidade que poderia fazer com que nosso mundo relativo fosse o reflexo de um mundo absoluto mais profundo. Em Leibniz, nosso mundo relativo é o único existente, mundo que repele outros mundos possíveis, já que ele é relativamente o melhor. Entre uma infinidade de mundos possíveis e incompossíveis entre si, Deus escolhe o melhor ou o que tem mais realidade possível. Nesse sentido, sugere Deleuze: "Ao passo que o Bem era o critério de dois mundos, o melhor é o critério do mundo único e relativo” (DELEUZE, 1991, p.105).

Deus não criou Adão com o risco de fazê-lo pecar, mas criou o mundo em que Adão peca. Parte-se do mundo do mesmo modo como se parte de uma série de acontecimentos, pura emissão de singularidades, como assinala Deleuze: "Eis, por exemplo, três singularidades: ser o primeiro homem, viver num jardim de prazer, ter uma mulher saída de sua própria costela. E eis uma quarta: pecar" (DELEUZE, 1991, p.105). Essas singularidadesacontecimentos entram em relação com ordinários ou regulares, elas estão rodeadas de ordinários ou de regulares. Tudo é relevante ou singular na medida em que podemos conduzir, por toda parte, uma inflexão ou dobra que erige um ponto singular. Mas é possível afirmar ainda que tudo é ordinário, já que um ponto singular é tão-somente a coincidência de dois pontos ordinários. Segundo Deleuze, a filosofia de Leibniz corresponde a dois polos: “Tudo é regular! E Tudo é singular!” (DELEUZE, 1991, p.105). Apenas distinguimos singulares e ordinários ou regulares entre si.

Podemos prolongar, a cada vez, uma singularidade na vizinhança de outras singularidades sobre linhas regulares cujos valores são comuns. Surge, então uma quinta singularidade: "resistir à tentação" (DELEUZE, 1991, p.105). Esta singularidade não contradiz a quarta, pecar, de modo que tenhamos que escolher entre as duas. Isso acontece porque as linhas de prolongamento que partem da quinta singularidade em direção às outras três singularidades não convergem ou não passam pelos mesmos valores, como observa Deleuze: "não é o mesmo jardim" (DELEUZE, 1991, p.105). Há, antes, uma bifurcação. O mundo de Adão não-pecador é supostamente incompossível com este mundo-aqui, já que ele implica uma singularidade divergente das singularidades deste mundo. 
Parece-nos que em Leibniz há um tipo de cálculo das séries infinitas cujas regras são ditadas pelas convergências e divergências e, segundo Deleuze, a grande representação barroca desse aspecto é dada pelo autor no final da Teodiceia precisamente por causa do encaixe das narrações entre si e pela variação da relação entre o narrador e a narração (DELEUZE, 1991, p.107): "é um sonho de arquitetura: uma imensa pirâmide, que tem um vértice, mas não tem base, constituída por uma infinidade de aposentos, sendo cada um deles um mundo" (DELEUZE, 1991, p.105). Há um vértice, pois há um mundo melhor do que todos os outros e não há base porque os mundos se perdem no nevoeiro, e também porque não há um mundo derradeiro que poderia ser chamado de pior dentre os outros mundos. Em cada aposento há um Sexto Tarquínio com uma cifra na fronte que narra uma sequência de sua vida, ou de toda sua vida, de forma teatral, perto de um espesso livro. A cifra sugere que esse episódio esteja descrito amplamente em determinada página do livro em escala menor, enquanto as outras páginas remetem a outros acontecimentos do mundo a que Sexto pertence.

Esta é, segundo Deleuze: “...a combinação barroca do que se lê e do que se vê" (DELEUZE, 1991, p.105). Nos outros aposentos há outros Sextos e outros livros. Quando Sexto sai da casa de Júpiter, ora ele vai a Corinto, quando se torna um notável, ora outro Sexto vai à Trácia tornando-se um rei, mas ele também poderia retornar à Roma e violar Lucrécia, como acontece no primeiro aposento.Todas as singularidades aí descritas são divergentes, mas se convergem somente com a primeira delas: a saída do templo, em valores diferentes. Todos os Sextos são possíveis, embora façam parte de mundos incompossíveis.

\section{Os incompossiveis de Leibniz em Lynch}

Em um belíssimo filme de David Lynch, podemos vislumbrar os mundos incompossíveis de Leibniz. Mulholland drive nos dá a ver imagens de mundos enigmáticos (LYNCH, 2001). Como na Teodiceia de Leibniz, em Mulholland drive, os mesmos personagens coabitam dois mundos. Entretanto, nesse filme, tais personagens estão com os nomes trocados entre si e a história se desenrola em duas direções que ora se bifurcam, ora convergem. 
Tudo parece partir sempre do mesmo lugar, no quarto escuro com a colcha rosa. Ao longo do filme essa cena se repete e a cada vez mais detalhes deste quarto sombrio são expostos, até que enfim a cena apresenta uma mulher morta deitada na cama. Este é o primeiro indício de que algo se passara ali. Quando o que chamaremos de segundo mundo tem início, o mesmo caubói, que surge no primeiro mundo, diz à personagem que está deitada na cama: "Ei mocinha. Hora de acordar" (LYNCH, 2001, c.14). Desde então, se inicia o segundo mundo, a personagem Diane acorda com alguém batendo à sua porta, ela se levanta e vai atender. Essa sequência nos leva a pensar que Diane teria dormido ao longo de todo o primeiro mundo, pois na ação que nele se desenrola nada se passa nesse quarto, somente vemos o corpo de uma mulher estirado na cama. Este corpo supostamente poderia ter estado assim durante toda a apresentação do primeiro mundo e então esta mulher teria sido acordada pelo caubói no início do segundo mundo.

Este filme, a nosso ver, pode ser contado sob a perspectiva dos incompossíveis, já que por mais que tentemos montar uma única história, ela nunca se completa, pois há sempre algo que falta ou que não se encaixa na história. Supomos que se trata de, como afirma o próprio diretor: “...uma história de amor" (LYNCH, 2007). Todavia essa história é narrada sob duas perspectivas: na primeira delas, a personagem Betty chega em Los Angeles para iniciar sua carreira de atriz - como no segundo mundo, porém os acontecimentos que se sucedem são diferentes nos dois mundos - e encontra Rita, recém-saída de um acidente, no apartamento de sua tia. As duas se conhecem e, desde então, tentam descobrir quem é Rita, já que esta personagem teria perdido a memória no acidente de carro. A partir daí elas se envolvem e mantêm um relacionamento amoroso, enquanto tentam descobrir a identidade perdida de Rita.

Nesse sentido, Lynch nos parece profundamente deleuziano, apesar de deliberadamente leibniziano, na medida em que desfaz inteiramente a identidade de Rita, cujo nome a personagem inventou ao ver o cartaz de Rita Hayworth quando esta estrelava Gilda (Vidor, 1946). A personagem Rita não tem nome, o que configura a perda da identidade pessoal, ou a impessoalidade, além do fato de que os personagens e os nomes, nos dois mundos, estão trocados entre si. Na segunda perspectiva, além de a história ser narrada de trás para frente, o que parece acontecer no filme 
todo, segundo nosso ponto de vista, tudo indica que a personagem Diane, que no primeiro mundo é Betty, teria encomendado a morte de Camilla Rhodes por amor ou, se quisermos acrescentar alguns indícios que Lynch introduz no filme, também por inveja de Camilla.

Várias são as coincidências apresentadas nesse filme, mas gostaríamos de ressaltar o fato de que esse filme nos parece ser profundamente leibniziano, já que as histórias se cruzam, os nomes, os personagens, os acontecimentos. A trama é única, porém os mundos são incompossíveis, o que não quer dizer contraditório. A história se inicia do mesmo modo nos dois mundos, mas os desdobramentos diferem: ora a personagem de Diane é Betty, ora é a própria Diane; ora Diane ou Betty acaba de chegar em Los Angeles e conhece Rita ou Camilla, ora elas teriam se conhecido num set de filmagem e teriam se apaixonado, mas quando Camilla anuncia seu casamento com um diretor de cinema, Diane fica com ciúme e/ou inveja mortal e acaba por encomendar a morte de Camilla. As histórias estão todas cruzadas, mas não é possível montar uma única história porque sempre faltará algo, ou algo não se encaixará.

Essa bifurcação que surge na vizinhança da qual as séries divergem, abre um labirinto barroco onde as séries infinitas, ora convergem, ora divergem, formando uma trama de tempo que abarca todos os mundos possíveis, ou todas as possibilidades. O personagem Adam Kisher, por exemplo, surpreende sua mulher com outro homem e se separa dela. Todavia a casa onde ele mora é a mesma em que ele reside no segundo mundo. Isso se evidencia quando, no segundo mundo, ele afirma que ficou com a casa e a piscina e sua mulher ficou com o limpador de piscina, ou seja, com quem ela o teria traído no primeiro mundo: "Fiquei com a piscina, e ela com o cara que limpava a piscina. Tive vontade de dar um RollsRoyce para o juiz" (LYNCH, 2007, c.15).

Na obra de David Lynch, todos os desenlaces se produzem e cada um deles pode ser o ponto de partida para outras bifurcações. Adam Kischer, por exemplo, no primeiro mundo, parece ser o diretor do filme Silvia North story e no segundo mundo não, já que Diane afirma ter conhecido Camilla Rhodes no set de Silvia North story, no qual o diretor é Bob Rooker, personagem diferente de Adam Kisher. Podemos ver a mistura das histórias que se bifurcam, histórias que divergem e nas quais as séries se desenvolvem simultaneamente em mundos incompossíveis. Camilla 
não pode ter conhecido Diane no mesmo mundo em que conheceu Betty, já que num mundo elas se conheceram no set de filmagem, no outro mundo elas se conhecem na casa da tia de Betty. Também não podem ser as mesmas personagens, já que seus nomes estão trocados, mas as séries se cruzam o tempo todo. A frase "this is the girl"3 é afirmada nos dois mundos, correspondendo ao mesmo nome, para diferentes personagens em situações distintas.

Entretanto, vemos a predominância de uma série que seria o melhor dos mundos possíveis, pois não se pode trazer à existência todos os incompossíveis ao mesmo tempo, mas sim escolher um, o melhor. A incompossibilidade é uma correlação original que se distingue da contradição e da impossibilidade. Nesse sentido, há contradições locais, em relação aos personagens com nomes trocados, por exemplo, Dianeassassina ou pecadora e Diane ou Betty amiga de Camilla ou Rita, nãopecadora. O que, em Leibniz, impede Deus de trazer à existência todos os possíveis, mesmo incompossíveis é que ele seria um Deus mentiroso e trapaceiro. Nesse sentido, observa Deleuze: “Deus joga mas dá regras ao jogo [...] A regra é que mundos possíveis não podem passar à existência se forem incompossíveis com aqueles que Deus escolheu" (DELEUZE, 1991, p.109).

Se o melhor dos mundos possíveis é aquele relativo, o único existente, que repele outros mundos possíveis porque ele é o melhor dos mundos e se, entre os mundos compossíveis e incompossíveis, Deus escolhe o melhor dentre eles ou o que tem mais realidade possível, então consideramos que o melhor dos mundos possíveis, nesse caso, é o mundo no qual a história nos parece mais real, a do segundo mundo. Se observarmos a trama, veremos que a história poderia perfeitamente ser explicada a partir da chegada de Diane em Los Angeles. Posteriormente ela conheceria Camilla no set de Silvia North story e elas iniciariam uma relação amorosa que culminaria quando Camilla anuncia seu casamento com o diretor de cinema. Diane não suportaria esse dado e, por isso, mandaria matar Camilla. Julgamos que este é o melhor dos mundos possíveis, pois ele nos parece mais real e ainda porque vários indícios que aparecem no primeiro mundo são compossíveis com o segundo, conforme afirmamos anteriormente, o que faz com que a história, apesar da bifurcação seja uma única história. 
A dramatização em Gilles Deleuze se direciona, então, ao continuum ideal do mundo de Leibniz. Mundo barroco que comporta os compossíveis e os incompossíveis, a convergência e a divergência. Mundo expresso no cinema de David Lynch, onde as séries se encontram e se bifurcam. Mundo da vice-dicção e não da contradição, que emerge do subsolo dionisíaco, sob a aparente filosofia apolínea.

\footnotetext{
${ }^{1}$ A esse respeito cf. SAUVAGNAR GUES, Anne. Deleuze: l'empirisme transcendantal. Paris: PUF, 2009. p. 209-237. Para a autora, o Comunicado de Deleuze possibilita acompanhar o percurso teórico que vai de Proust I à Ideia de Diferença e repetição. Cf. Deleuze, Gilles. Proust e os signos, 2003.

2 Para essa distinção nos servimos da equivalência estabelecida no glossário da edição brasileira de Diferença e repetição: différentiation = diferençação, différenciation = diferenciação. DELEUZE, Gilles. Diferença e repetição. 2006.

3 Em português: "esta é a garota”. A esse respeito cf. TOUDOIRE-SOURLAPIERRE, Frédérique. "This is the girl" in: Mulholland drive. Sous la direction de Nathalie David \& Cyrille Habert. Paris: Les Éditions de La Transparence, 2007.
}

\section{Referências bibliográficas}

DAVID, N.; HABERT, C. (Sous la Direction). 2007. Mulholland drive. Paris: Les Éditions de La Transparence.

DELEUZE, G. A ilha deserta e outros textos. Textos e entrevistas (19531974). Edição preparada por David Lapoujade. Organização da Tradução de Luiz B. L. Orlandi. São Paulo: Iluminuras, 2006. . A dobra: Leibniz e o barroco. $2^{\text {a }}$ Edição. Tradução de Luiz B. Orlandi. Campinas: Papirus, 2000.

Deux régimes de fous. Textes et entretiens 1975-1995. Édition préparée par David Lapoujade. Paris: Les Éditions de Minuit, 2003. Diferença e repetição. $2^{\text {a }}$ Edição revista e atualizada. Tradução de Luiz B. L. Orlandi e Roberto Machado. Rio de Janeiro: Graal, 2006. 
. Nietzsche et la philosophie. $4^{\mathrm{a}}$ édition. Paris: PUF, 2003.

. Proust e os signos. Tradução de Antonio Piquet e Roberto

Machado. Rio de Janeiro: Forense Universitária. 2003.

DELEUZE, G; GUATTARI, F. O que é a filosofia? Tradução de Bento Prado Jr. e Alberto Alonso Muñoz. São Paulo: Ed. 34 Letras, 1992.

DUFOUR, É. David Lynch: matière, temps et image. Paris:Vrin, 2008. JOUSSE, T. David Lynch: le livre. Paris: Cahiers du cinéma Éditions, 2007.

LYNCH, D. Mulhollanda drive. EUA, 145 min., 2001. . Conversations avec Chris Rodley. Paris: Les Cahiers du cinéma, 2007.

SAUVAGNAR GUES. A. Deleuze: l'empirisme transcendantal. Paris: PUF, 2009.

SCHÉRER, R. Regards sur Deleuze. Paris: Kimé, 1998.

TOUDOIRE-SOURLAPIERRE, F. “This is the girl” in: Mulholland drive. Sous la direction de Nathalie David \& Cyrille Habert. Paris: Les Éditions de La Transparence, 2007.

VIDOR, C. Gilda. EUA, 110 min., 1946. 